\title{
Análise genética em um dialelo de alface ${ }^{(1)}$
}

\author{
Francisco José da Silva Lédo(2), Vicente Wagner Dias Casali(3)
} Cosme Damião Cruz $^{(4)}$ e Carlos Alberto da Silva Lédo(5)

\begin{abstract}
Resumo - Este trabalho teve por objetivo estimar parâmetros genéticos em um dialelo de alface, segundo o método de Jinks \& Hayman. O experimento foi conduzido em casa de vegetação, na Universidade Federal de Viçosa, no período de 20/10 a 12/12/96. O delineamento experimental adotado foi o de blocos casualizados, com três repetições. Utilizaram-se vasos com 4,5 $\mathrm{dm}^{3}$ de substrato e uma planta por vaso (parcela). Foram avaliadas seis cultivares de alface (Vitória de Verão, Nativa, Regina de Verão, Maravilha de Verão, Grand Rapids e Mimosa) e seus respectivos híbridos $\mathrm{F}_{1}$. Avaliaram-se os seguintes caracteres: matéria fresca da parte aérea (MFPA); matéria seca da parte aérea (MSPA), folhas (MSF) e raiz (MSR); número de folhas/planta (NUF); e comprimento do caule (CC). Foram detectadas evidências de epistasia nos caracteres MSPA, NUF e CC. Na MFPA a variação de natureza aditiva contribuiu predominantemente para a variabilidade genética observada entre pais e seus híbridos $\mathrm{F}_{1}$. Evidenciou-se a predominância de efeitos gênicos de dominância no controle gênico dos caracteres MSF e MSR. As estimativas do coeficiente de determinação genotípico no sentido amplo $\left(\hat{\mathrm{h}}_{\mathrm{A}}^{2}\right)$ sobre MFPA, MSF e MSR foram de 0,84, 0,85 e 0,90, respectivamente, e restrito ( $\left.\hat{\mathrm{h}}_{\mathrm{R}}^{2}\right) 0,66,0,45$ e 0,49 .
\end{abstract}

Termos para indexação: Lactuca sativa, características agronômicas, controle genético, parâmetros genéticos, métodos de melhoramento.

\section{Genetic analysis in a lettuce diallel}

Abstract - This work aimed to estimate genetic parameters in a lettuce diallel, according to the Jinks \& Hayman's method. The experiment was carried out in a greenhouse, at the Universidade Federal de Viçosa, from October 20 to December 12, 1996. The experimental design used was a randomized complete blocks, with three replications. Pots with $4,5 \mathrm{dm}^{3}$ of substrate and one plant/pot (plot) were used. Six lettuce cultivars and their respective $F_{1}$ hybrids were evaluated. The following characters were evaluated: fresh matter of aerial part (FMAP); dry matter of aerial part (DMAP), leaves (DML) and roots (DMR); number of leaves/plant (NUL); and stem height (SH). Some evidences of epistasis were detected for DMAP, NUL and SH characters. In FMAP the variation of additive nature contributes predominantly to the genetic variability observed between parents and $\mathrm{F}_{1}$. The prevalence of dominance gene effects on the control of DML and DMR characters were evident. The estimates of genotypic determination coefficient on wide sense $\left(\hat{\mathrm{h}}_{\mathrm{W}}^{2}\right)$ in FMAP, DML and DMR were 0.84, 0.85 and 0.90 , and restricted sense $\left(\hat{\mathrm{h}}_{\mathrm{R}}^{2}\right) 0.66,0.45$ and 0.49

Index terms: Lactuca sativa, agronomic characters, genetic control, genetic parameters, breeding methods.

(1) Aceito para publicação em 8 de dezembro de 2000

(2) Embrapa-Centro de Pesquisa Agroflorestal do Acre (CPAFAcre), Caixa Postal 392, CEP 69901-180 Rio Branco, AC. E-mail: fledo@cpafac.embrapa.br

(3) Universidade Federal de Viçosa (UFV), Dep. de Fitotecnia CEP 36571-000 Viçosa, MG. E-mail: vwcasali@mail.ufv.br

(4)UFV, Dep. de Biologia Geral. E-mail: cdcruz@mail.ufv.br

(5) Universidade Federal de Lavras (UFLA), Dep. de Biologia, CEP 37200-000 Lavras, MG. Bolsista do CNPq E-mail: ledo@ufla.br

\section{Introdução}

No melhoramento de plantas, o conhecimento da natureza do controle genético de um caráter é de grande importância para a condução eficiente de um programa de melhoramento, orientando na escolha do melhor procedimento de seleção e dos métodos de melhoramento mais eficientes na condução das populações segregantes (Vencovsky \& Barriga, 1992; 
Ramalho et al., 1993; Cruz \& Regazzi, 1994). Entre os delineamentos genéticos disponíveis, os cruzamentos dialélicos se destacam, provendo estimativas de parâmetros úteis na seleção de genitores para hibridação e no entendimento dos efeitos genéticos envolvidos na determinação dos caracteres (Cruz \& Regazzi, 1994).

Entre os métodos de análise dialélica disponíveis, o proposto por Jinks \& Hayman (1953) e Hayman (1954a, 1954b) não se baseia em modelos previamente estabelecidos, mas no conhecimento da natureza ambiental e genética de estatísticas (médias, variâncias, covariâncias) obtidas a partir de uma tabela dialélica, que fornecem informações sobre o controle genético do caráter em estudo, dos valores genéticos de genitores e dos limites de seleção dos caracteres em estudo (Vencovsky \& Barriga, 1992; Cruz \& Regazzi, 1994).

No melhoramento de hortaliças, vários autores vêm utilizando esse método para incrementar informações em diversos caracteres quantitativos de interesse, nas culturas do tomateiro (Maluf et al., 1982; Miranda et al., 1982; Amaral Júnior et al., 1999) e pimentão (Oliveira, 1997). Na alface, é comum a utilização de métodos de melhoramento que envolvam hibridação e seleção, principalmente o método genealógico (Ryder, 1986; Vecchia \& Kikuchi, 1989a, 1989b; Vecchia et al., 1999), e uma das dificuldades encontradas no processo seletivo é a falta de informações sobre a herança de características quantitativas de interesse. A obtenção dessas informações pode possibilitar maiores ganhos genéticos, aumentando a eficácia do programa de melhoramento com alface.

Este trabalho teve por objetivo determinar o controle gênico de alguns caracteres agronomicamente importantes, em um dialelo de seis cultivares de alface, com o propósito de obter subsídios para futuros programas de melhoramento.

\section{Material e Métodos}

O experimento foi conduzido em casa de vegetação, na Universidade Federal de Viçosa, no período de 20 de outubro (semeadura) a 12 de dezembro de 1996 (última colheita). Foram avaliadas seis cultivares de alface e 15 híbridos $F_{1}$ obtidos entre todos os pares de combinações das cultivares (genitores), desconsiderando os híbridos recíprocos. As cultivares utilizadas foram: Grand Rapids (crespa solta - origem Agroceres), Maravilha de Verão (lisa repolhuda - origem Top Seed), Mimosa (solta com bordas recortadas - origem Feltrin), Regina de Verão (lisa solta - origem Agroceres), Nativa (lisa solta - Banco de Germoplasma de Hortaliças da UFV, BGH 2429) e Vitória de Verão (crespa solta - origem Pak).

O delineamento experimental adotado foi o de blocos casualizados, com três repetições. Cada parcela era constituída de um vaso com uma planta. Utilizaram-se vasos de polietileno rígido, preenchidos com $4,5 \mathrm{dm}^{3} \mathrm{de}$ substrato, constituído da mistura de uma parte de areia lavada e duas partes de solo classificado como Latossolo variação Una (LU), coletado na UFV, à profundidade de 20 a $50 \mathrm{~cm}$

Foi realizada a correção do $\mathrm{pH}$ com base nas recomendações da Comissão de Fertilidade do Solo do Estado de Minas Gerais (1989). Na adubação mineral foram adicionados, em mg/dm ${ }^{3}$ : P, 500; N, 125; K, 150; S, 40; B, 2; $\mathrm{Cu}, 1 ; \mathrm{Zn}, 2$ e Mo, 0,3, fornecidos na combinação dos seguintes sais p.a: $\mathrm{K}_{2} \mathrm{SO}_{4}, \mathrm{NH}_{4} \mathrm{NO}_{3}, \mathrm{ZnSO}_{4} \cdot 7 \mathrm{H}_{2} \mathrm{O}$, $\mathrm{CuSO}_{4} \cdot 5 \mathrm{H}_{2} \mathrm{O}, \mathrm{H}_{3} \mathrm{BO}_{3}$ e $\left(\mathrm{NH}_{4}\right)_{6} \cdot \mathrm{Mo}_{7} \cdot \mathrm{O}_{24} \cdot 4 \mathrm{H}_{2} \mathrm{O}$; o $\mathrm{P}$ foi adicionado na forma de superfosfato triplo moído. $\mathrm{ON}$ foi todo aplicado em cobertura aos 3, 13 e 23 dias após o transplantio, utilizando-se um terço da dose total em cada época.

Aos 19 dias após a semeadura, as mudas com a raiz nua foram transplantadas para os vasos. Na condução do experimento, a umidade do solo foi mantida próximo aos $85 \%$ da capacidade de campo, com base no peso dos vasos determinado, a cada cinco dias. A colheita foi realizada aos 51,52 e 53 dias após a semeadura (uma repetição por dia), quando a maioria das plantas se aproximaram do seu máximo crescimento vegetativo com aspecto comerciável. As plantas foram colhidas cortando-se o caule no coleto, rente ao solo, e imediatamente pesadas, para determinação da matéria fresca. Em seguida, as folhas foram separadas do caule, para determinação do seu comprimento. As folhas, o caule e as raízes foram acondicionados em sacos de papel e colocados para secar em estufa com ventilação forçada a $65^{\circ} \mathrm{C}$, até peso constante, para determinação da matéria seca

Avaliaram-se os seguintes caracteres: matéria fresca da parte aérea (MFPA); matéria seca da parte aérea (MSPA), de folhas (MSF) e raiz (MSR); número de folhas com mais de $4 \mathrm{~cm}$ de comprimento por planta (NUF); e comprimento do caule em relação ao nível do solo (CC).

O uso do método proposto por Jinks \& Hayman (1953) e Hayman (1954a, 1954b) exige as seguintes pressuposições: segregação diplóide; genitores homozigóticos; ausência de efeito materno; ausência de alelismo múltiplo; genes distribuídos independentemente entre os genitores; e ausência de epistasia. De maneira conjunta, as falhas nas pressuposições foram avaliadas por testes de suficiência 
do modelo aditivo-dominante. Assim, com os valores da covariância entre os genitores e a r-ésima linha $\left(\hat{\mathrm{W}}_{\mathrm{r}}\right)$ e da variância dentro da linha ou coluna $\left(\hat{\mathrm{V}}_{\mathrm{r}}\right)$, foram aplicados três testes para avaliar a heterogeneidade $\operatorname{de} \hat{\mathrm{W}}_{\mathrm{r}}-\hat{\mathrm{V}}_{\mathrm{r}}$ : a) a variação de $\hat{\mathrm{W}}_{\mathrm{r}}-\hat{\mathrm{v}}_{\mathrm{r}}$ foi avaliada por meio da análise de variância, considerando-se como fonte de variação as repetições das tabelas e as linhas (ou entradas da tabela dialélica) dentro de cada tabela, se o efeito de linha for significativo, há indicativo de falhas nas pressuposições; b) com base na análise de regressão linear de $\hat{\mathrm{W}}_{\mathrm{r}}$ em função de $\hat{\mathrm{V}}_{\mathrm{r}}$, foi realizado um teste sobre o coeficiente de regressão, pela estatística t, em que foi verificada a significância do coeficiente angular da reta $\left(\mathrm{H}_{0}: b=1\right.$ vs. $\left.\mathrm{H}_{\mathrm{a}}: \mathrm{b}^{\neq} 1\right)$; c) ponderaram-se $\hat{\mathrm{W}}_{\mathrm{r}}$ e $\hat{\mathrm{V}}_{\mathrm{r}}$ por meio de rotação de $45^{\circ}$ dos eixos representados por $\hat{W}_{\mathrm{r}}^{\prime}$ e $\hat{\mathrm{V}}_{\mathrm{r}}^{\prime}$, e em seguida foi testado o coeficiente angular da reta após a rotação $\left(\mathrm{H}_{0}: b^{\prime}=0\right.$ vs. $\left.\mathrm{H}_{\mathrm{a}}: \mathrm{b}^{\prime} \neq 0\right)$

Nos caracteres que evidenciaram a viabilidade de utilização do modelo aditivo-dominante no estudo genético, foram estimados, a partir das estatísticas obtidas da tabela dialélica, os seguintes componentes genéticos e ambiental: $\hat{\varepsilon}$ - componente de variância ambiental; $\hat{D}$ - componente de variância associado aos efeitos aditivos; $\hat{\mathrm{H}}_{1}$ e $\hat{\mathrm{H}}_{2}$ - componentes de variância associados aos desvios de dominância; $\hat{\mathrm{h}}^{2}$ - componente quadrático determinado pela diferença de média entre híbridos e pais; $\hat{\mathrm{F}}$ - componente associado à covariância entre efeitos aditivos e nãoaditivos; e $\hat{D}-\hat{H}_{1}$ - componente que expressa a diferença entre efeitos gênicos aditivos e dominantes.

Também foram estimados os seguintes parâmetros genéticos: $\sqrt{\hat{\mathrm{H}}_{1} / \hat{\mathrm{D}}}-$ grau médio de dominância; $\hat{\mathrm{H}}_{2} / 4 \hat{\mathrm{H}}_{1}$ distância dos alelos - simetria; $\hat{\mathrm{K}}_{\mathrm{D}} / \hat{\mathrm{K}}_{\mathrm{R}}$ - relação dominante/recessivo; $\hat{\mathrm{h}}^{2} / \hat{\mathrm{H}}_{2}$ - número de genes com dominância; $\hat{\mathrm{h}}_{\mathrm{R}}^{2}$ - coeficiente de determinação no sentido restrito; $\hat{\mathrm{h}}_{\mathrm{A}}^{2}$ coeficiente de determinação no sentido amplo; correlações entre os valores médios dos genitores $\left(\overline{\mathrm{Y}}_{\mathrm{rr}}\right)$ e da soma da covariância, entre médias dos genitores e médias da r-ésima linha $\left(\hat{\mathrm{W}}_{\mathrm{r}}\right)$, e da variância entre médias da r-ésima linha $\left(\hat{\mathrm{V}}_{\mathrm{r}}\right)$; valores esperados das coordenadas $\hat{\mathrm{W}}_{\mathrm{R}}, \hat{\mathrm{V}}_{\mathrm{R}} \mathrm{e} \hat{\mathrm{W}}_{\mathrm{D}}$, $\hat{\mathrm{V}}_{\mathrm{D}}$; e valor predito para o genitor com máxima concentração de alelos dominantes $\left(\hat{\mathrm{Y}}_{\mathrm{D}}\right)$ e recessivos $\left(\hat{\mathrm{Y}}_{\mathrm{R}}\right)$. O significado dos componentes e parâmetros é explicado por Hayman (1954b) e Cruz \& Regazzi (1994).

A significância de cada componente foi testada pela estatística t, obtida pela divisão das estimativas do efeito pelo respectivo desvio-padrão. Quando os valores de $t$ foram acima de 1,96, foram considerados significativos a 5\% de probabilidade (Singh \& Chaudhary, 1979). Para obtenção do desvio-padrão de cada estimativa, as variâncias dos componentes foram obtidas consultando-se a tabela apresentada por Ferreira (1985). As análises foram execu- tadas com auxílio do programa computacional GENES (Cruz, 1997).

\section{Resultados e Discussão}

Em todos os caracteres estudados, houve significância do efeito de genótipos (cultivares + respectivos híbridos $\mathrm{F}_{1}$ ) a $1 \%$ de significância pelo teste F. Os coeficientes de variação experimental (\%) obtidos em MFPA, MSPA, MSF, MSR, NUF e CC foram de 6,$89 ; 7,18 ; 6,69 ; 16,01 ; 8,30$ e 18,99 , respectivamente. Assim, procedeu-se à análise genética de cada caráter, segundo o método de análise dialélica proposto por Jinks \& Hayman (1953) e Hayman (1954a, 1954b).

As restrições impostas na utilização do método de Hayman (1954a, 1954b) foram avaliadas por testes de suficiência do modelo aditivo-dominante, com base na heterogeneidade de $\hat{\mathrm{W}}_{\mathrm{r}}-\hat{\mathrm{V}}_{\mathrm{r}}$. Na Tabela 1, são apresentados os resultados da aplicação de três testes na avaliação da adequação dos dados ao modelo aditivo-dominante dos caracteres avaliados. Os caracteres MFPA e MSF apresentaram ausência de significância nos três testes, evidenciando a adequação às restrições impostas e a viabilidade de utilização do modelo aditivo-dominante. Para MSR, houve adequação ao modelo aditivo-dominante após a transformação logarítmica dos dados. Segundo Mather \& Jinks (1984), quando há falha no ajuste ao modelo aditivo-dominante, o uso de uma escala transformada pode remover ou reduzir substancialmente a interdependência dos efeitos dos genes, tornando possível a sua utilização. Nos demais caracteres, a ocorrência de significância em pelo menos um dos testes do modelo aditivo-dominante evidenciou a ocorrência de epistasia e a não-adequação do modelo. Em razão disso, os caracteres MSPA, NUF e CC foram excluídos da análise.

Os resultados referentes à MFPA evidenciam que os componentes associados aos efeitos aditivos $(\hat{D})$ foram mais importantes que os associados aos efeitos da dominância ( $\hat{h}^{2}, \hat{\mathrm{H}}_{1}$ e $\hat{\mathrm{H}}_{2}$ ), o que é constatado também pelo valor positivo e significativo de $\hat{D}-\hat{\mathrm{H}}_{1}$ (Tabela 2). A estimativa do grau médio de dominância $\left(\sqrt{\hat{\mathrm{H}}_{1} / \hat{\mathrm{D}}}\right)$, de 0,75 , indica a existência de dominância parcial entre os alelos que atuam no controle gênico do caráter (Tabela 3), o que é verificado também pelo fato de a reta de regressão de $\hat{\mathrm{W}}_{\mathrm{r}}$ em $\hat{\mathrm{V}}_{\mathrm{r}}$ interceptar a ordenada acima da origem (Figura 1). 
Tabela 1. Teste de suficiência do modelo genético aditivo-dominante com base na análise de variância dos valores de $\hat{\mathrm{W}}_{\mathrm{r}}-\hat{\mathrm{V}}_{\mathrm{r}}$ e na análise da regressão linear de $\hat{\mathrm{W}}_{\mathrm{r}}$, em função de $\hat{\mathrm{W}}_{\mathrm{r}}$, nos caracteres matéria fresca da parte aérea (MFPA), matéria seca da parte aérea (MSPA), das folhas (MSF) e da raiz (MSR), número de folhas/planta (NUF) e comprimento do caule (CC), segundo o método de Hayman (1954a, 1954b). Viçosa, UFV, 1996

\begin{tabular}{|c|c|c|c|c|}
\hline \multirow[t]{2}{*}{ Caráter } & \multirow{2}{*}{$\frac{\text { Anova } \hat{\mathrm{W}}_{\mathrm{r}}-\hat{\mathrm{V}}_{\mathrm{r}}}{\text { QM Linhas }}$} & \multicolumn{3}{|c|}{ Regressão $\left[\hat{\mathrm{W}}_{\mathrm{r}}=1 / 4\left(\hat{\mathrm{D}}-\hat{\mathrm{H}}_{1}\right)+\mathrm{b} \hat{\mathrm{V}}_{\mathrm{r}}\right]$} \\
\hline & & $\hat{b} \pm$ Variância & $\mathrm{t}\left(\mathrm{H}_{\mathrm{o}}: \mathrm{b}=1\right)$ & $\mathrm{F}=\mathrm{t}^{2}\left(\mathrm{H}_{\mathrm{o}}: \mathrm{b}^{\prime}=0\right)^{(1)}$ \\
\hline$\overline{\mathrm{MFPA}}$ & $71551,02^{\mathrm{ns}}$ & $0,885 \pm 0,0366$ & $-0,601^{\mathrm{ns}}$ & $0,184^{\mathrm{ns}}$ \\
\hline MSPA & $39,954^{* *}$ & $0,205 \pm 0,0369$ & $-4,143^{*}$ & $2,112^{\mathrm{ns}}$ \\
\hline MSF & $1,1234108^{\mathrm{ns}}$ & $0,569 \pm 0,0421$ & $-2,102^{\mathrm{ns}}$ & $1,238^{\mathrm{ns}}$ \\
\hline MSR & $0,6901^{*}$ & $0,572 \pm 0,0593$ & $-1,758^{\mathrm{ns}}$ & $0,894^{\mathrm{ns}}$ \\
\hline $\log (\mathrm{MSR})$ & $0,0000987^{\mathrm{ns}}$ & $0,663 \pm 0,0422$ & $-1,642^{\mathrm{ns}}$ & $0,954^{\mathrm{ns}}$ \\
\hline NUF & $69,995^{\mathrm{ns}}$ & $0,332 \pm 0,0488$ & $-3,025^{*}$ & $1,572^{\mathrm{ns}}$ \\
\hline $\mathrm{CC}$ & $89032,687^{* *}$ & $0,542 \pm 0,0312$ & $-2,595^{\mathrm{ns}}$ & $1,647^{\mathrm{ns}}$ \\
\hline
\end{tabular}

${ }^{(1)}$ Teste $\mathrm{F}$, ponderando-se os valores médios de $\hat{\mathrm{W}}_{\mathrm{r}} \mathrm{e} \hat{\mathrm{V}}_{\mathrm{r}}$, por meio de sua rotação de $45^{\circ}$. ns Não-significativo. ${ }^{*} \mathrm{e}{ }^{* *}$ Significativo a $5 \%$ e $1 \%$ de probabilidade, respectivamente, pelo teste $\mathrm{F}$ e pelo teste $\mathrm{t}$.

Tabela 2. Estimativas dos componentes genéticos e não-genéticos dos caracteres matéria fresca da parte aérea (MFPA), matéria seca das folhas (MSF) e matéria seca da raiz com transformação logarítmica (MSR), segundo o método de Hayman (1954a, 1954b). Viçosa, UFV, 1996.

\begin{tabular}{lccccccc}
\hline Caráter & \multicolumn{7}{c}{ Componente $^{(1)} \pm$ desvio-padrão $^{(2)}$} \\
\cline { 2 - 7 } & $\hat{\varepsilon}$ & $\hat{\mathrm{D}}$ & $\hat{\mathrm{H}}_{1}$ & $\hat{\mathrm{H}}_{2}$ & $\hat{\mathrm{h}}^{2}$ & $\hat{\mathrm{F}}$ & $\hat{\mathrm{D}}-\hat{\mathrm{H}}_{1}$ \\
\hline MFPA & 142,57 & 1370,50 & 768,87 & 660,63 & 1099,18 & 308,03 & 601,62 \\
& $\pm 54,87^{*}$ & $\pm 128,98^{*}$ & $\pm 377,80^{*}$ & $\pm 329,12^{*}$ & $\pm 193,88^{*}$ & $\pm 310,11^{\mathrm{ns}}$ & $\pm 163,24^{*}$ \\
MSF & 0,3039 & 0,5448 & 3,7161 & 3,0962 & 8,9026 & $-0,5893$ & $-3,1712$ \\
& $\pm 0,1387^{*}$ & $\pm 0,3260^{\mathrm{ns}}$ & $\pm 0,9550^{*}$ & $\pm 0,8319^{*}$ & $\pm 0,4901^{*}$ & $\pm 0,7839^{\mathrm{ns}}$ & $\pm 0,4126^{*}$ \\
Log (MSR) & $0,184510^{2}$ & $1,1679.10^{-2}$ & $3,583710^{-2}$ & $3,06210^{-2}$ & $6,147110^{-2}$ & $-0,134610^{-2}$ & $-2,415810^{-2}$ \\
& $\pm 0,16110^{-2 \mathrm{~ns}}$ & $\pm 0,382.10^{-2^{*}}$ & $\pm 1,12110^{-2^{*}}$ & $\pm 0,97710^{-2^{*}}$ & $\pm 0,57510^{-2^{*}}$ & $\pm 0,92010^{-2 \mathrm{~ns}}$ & $\pm 0,48410^{-2^{*}}$ \\
\hline
\end{tabular}

(1) $\hat{\varepsilon}$ : componente de variância ambiental; $\hat{\mathrm{D}}$ : componente de variância associado aos efeitos aditivos; $\hat{\mathrm{H}}_{1}$ e $\hat{\mathrm{H}}_{2}$ : componentes de variância associados aos desvios de dominância; $\hat{\mathrm{h}}^{2}$ : componente quadrático determinado pela diferença de média entre híbridos e pais; $\hat{\mathrm{F}}$ : componente associado à covariância entre efeitos aditivos e não-aditivos; $\hat{\mathrm{D}}$ - $\hat{\mathrm{H}}_{1}$ : componente que expressa a diferença entre efeitos gênicos aditivos e dominantes. ${ }^{\left({ }^{2}\right)}$ Valores de $t$ obtidos pela

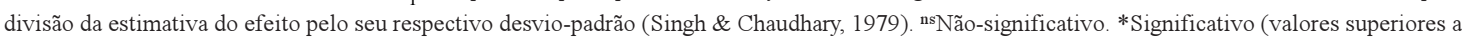
$1,96)$ a $5 \%$ de probabilidade

Tabela 3. Estimativas dos parâmetros genéticos e não-genéticos dos caracteres matéria fresca da parte aérea (MFPA), matéria seca das folhas (MSF) e matéria seca da raiz com transformação logarítmica (MSR), segundo o método de Hayman (1954a, 1954b). Viçosa, UFV, 1996

\begin{tabular}{lcccccc}
\hline Caráter & \multicolumn{5}{c}{ Estimativas dos parâmetros ${ }^{(1)}$} \\
\cline { 2 - 6 } & $\sqrt{\hat{\mathrm{H}}_{1} / \hat{\mathrm{D}}}$ & $\hat{\mathrm{H}}_{2} / 4 \hat{\mathrm{H}}_{1}$ & $\hat{\mathrm{K}}_{\mathrm{D}} / \hat{\mathrm{K}}_{\mathrm{R}}$ & $\hat{\mathrm{h}}^{2} / \hat{\mathrm{H}}_{2}$ & $\hat{\mathrm{h}}_{\mathrm{R}}^{2}$ & $\hat{\mathrm{h}}_{\mathrm{A}}^{2}$ \\
\hline MFPA & 0,749 & 0,215 & 1,353 & 1,664 & 0,656 & 0,840 \\
MSF & 2,612 & 0,208 & 0,657 & 2,875 & 0,449 & 0,845 \\
Log (MSR) & 1,752 & 0,214 & 0,936 & 2,008 & 0,490 & 0,901
\end{tabular}

(1) $\sqrt{\hat{\mathrm{H}}_{1} / \hat{\mathrm{D}}}$ : grau médio de dominância; $\hat{\mathrm{H}}_{2} / 4 \hat{\mathrm{H}}_{1}$ : distância dos alelos - simetria; $\hat{\mathrm{K}}_{\mathrm{D}} / \hat{\mathrm{K}}_{\mathrm{R}}$ : relação dominante/recessivo; $\hat{\mathrm{h}}^{2} / \hat{\mathrm{H}}_{2}:$ número de genes com dominância; $\hat{\mathrm{h}}_{\mathrm{R}}^{2}$ : coeficiente de determinação no sentido restrito; $\hat{\mathrm{h}}_{\mathrm{A}}^{2}$ : coeficiente de determinação no sentido amplo. 

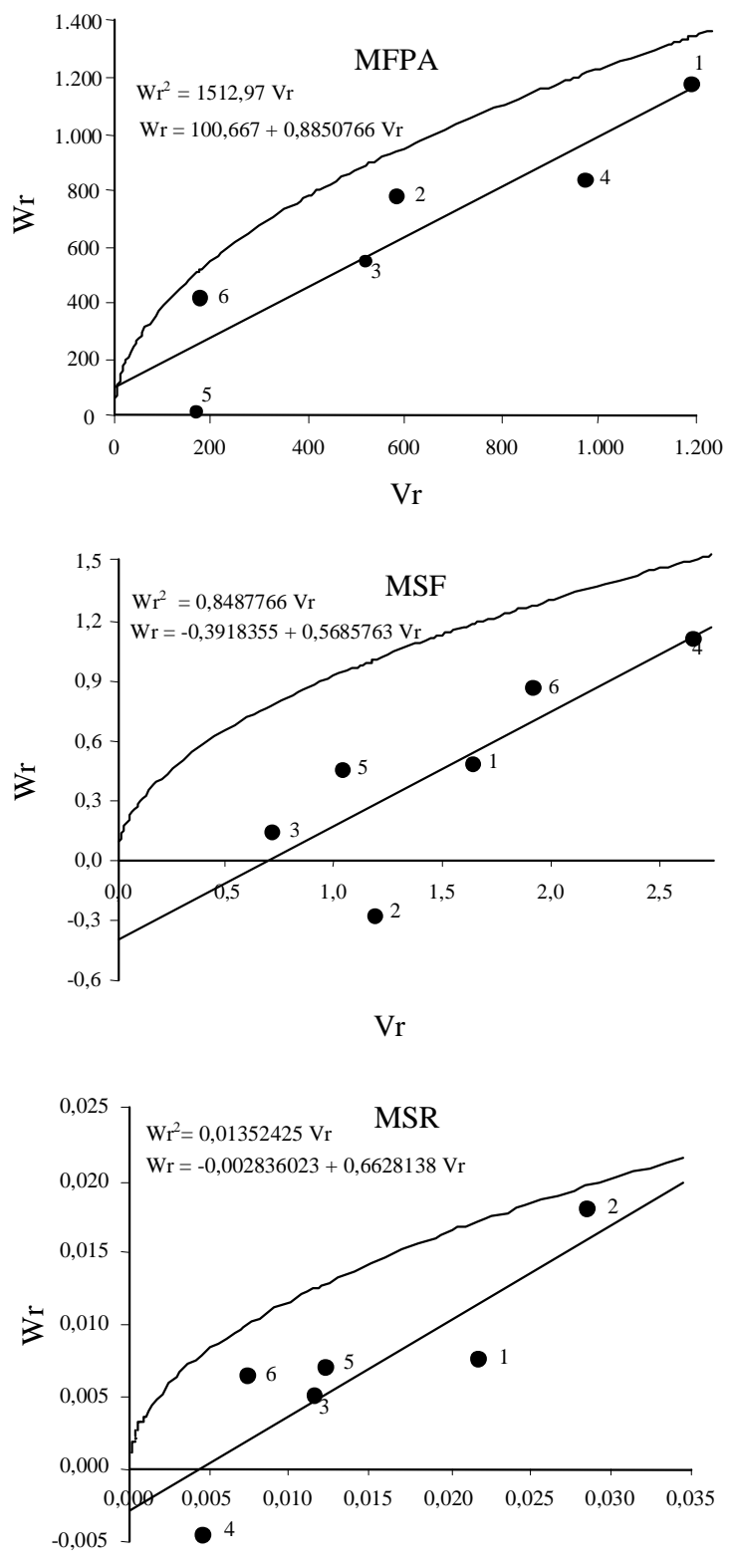

$\mathrm{Vr}$

$\begin{array}{ll}\text { 1. Grand Rapids } & \text { 4. Nativa } \\ \text { 2. Maravilha de Verão } & \text { 5. Regina de Verão } \\ \text { 3. Mimosa } & \text { 6. Vitória de Verão }\end{array}$

Figura 1. Regressões de $\hat{\mathrm{W}}_{\mathrm{r}}$ em $\hat{\mathrm{V}}_{\mathrm{r}}$ dos caracteres matéria fresca da parte aérea (MFPA), matéria seca das folhas (MSF) e matéria seca da raiz com transformação logarítmica (MSR). Viçosa, UFV, 1996.
As estimativas negativas e significativas de $\hat{\mathrm{D}}-\hat{\mathrm{H}}_{1}$ na MSF e MSR evidenciam a predominância de efeitos gênicos de dominância no controle gênico desses caracteres, com existência de relação de sobredominância entre os alelos dos genes não-fixados, já que as estimativas do grau médio de dominância $\left(\sqrt{\hat{\mathrm{H}}_{1} / \hat{\mathrm{D}}}\right)$ foram superiores à unidade, e a reta de regressão de $\hat{\mathrm{W}}_{\mathrm{r}}$ em $\hat{\mathrm{V}}_{\mathrm{r}}$ interceptou a ordenada abaixo da origem (Figura 1).

As estimativas da razão $\hat{\mathrm{H}}_{2} / 4 \hat{\mathrm{H}}_{1}$ nos caracteres MFPA, MSF e MSR foram inferiores a 0,25, o que indica que os alelos de efeitos favoráveis ou desfavoráveis apresentam distribuição assimétrica nos genitores, o que é evidenciado também pela estimativa dos valores da relação dominante/recessivo $\left(\hat{\mathrm{K}}_{\mathrm{D}} / \hat{\mathrm{K}}_{\mathrm{R}}\right)$, na qual se verifica que na MSF existe predominância de alelos recessivos $(0,657)$, e na MFPA, alelos dominantes $(1,353)$. As estimativas do número de genes com dominância ou blocos gênicos, dado por $\hat{\mathrm{h}}^{2} / \hat{\mathrm{H}}_{2}$, indicam a existência de pelo menos dois genes, ou blocos gênicos, nos caracteres MFPA e MSR, e três na MSF. Entretanto, este estimador subestima o número de genes, que exibe pouca ou nenhuma dominância (Cruz \& Regazzi, 1994).

As diferenças encontradas entre as estimativas do coeficiente de determinação genotípico nos sentidos amplo, $\hat{\mathrm{h}}_{\mathrm{A}}^{2}(0,84,0,85$ e 0,90$)$, e restrito, $\hat{\mathrm{h}}_{\mathrm{R}}^{2}(0,66,0,45$ e 0,49$)$, observados nos caracteres MFPA, MSF e MSR, respectivamente, evidenciam que ambos os efeitos gênicos, aditivos e nãoaditivos, estão envolvidos no controle genético desses caracteres (Tabela 3 ).

A correlação (r) de $-0,47$ entre $\overline{\mathrm{Y}}_{\mathrm{rr}}$ e $\hat{\mathrm{W}}_{\mathrm{r}}+\hat{\mathrm{V}}_{\mathrm{r}}$ na MFPA, de baixa magnitude, indica que genes dominantes atuam para aumentar a expressão do caráter, mas de forma não-exclusiva (Tabela 4). Os genitores Regina de Verão e Vitória de Verão foram os que apresentaram maior concentração de alelos dominantes, enquanto Grand Rapids e Nativa retiveram maior concentração de alelos recessivos (Tabela 5 e Figura 1). As correlações (r) negativas e de moderada magnitude obtidas para MSF $(-0,75)$ e MSR $(-0,88)$ mostram que alelos dominantes, predominantemente, mas não exclusivamente, atuam no sentido de aumentar a média desses caracteres. Apresentaram maior concentração de alelos dominantes na MSF os genitores Mimosa, Maravilha de Verão e 
Regina de Verão, e na MSR Nativa, sendo os mais favoráveis para obtenção de linhagens, em suas populações segregantes.

O genitor com máxima homozigose dominante na MSF deverá apresentar $\hat{\mathrm{W}}_{\mathrm{r}}+\hat{\mathrm{V}}_{\mathrm{r}}=-0,200\left(=\hat{\mathrm{W}}_{\mathrm{D}}+\hat{\mathrm{V}}_{\mathrm{D}}\right)$. Mimosa, que apresentou o valor mais próximo, está distante deste valor $(0,857)$, o que indica a possibilidade de obtenção de linhagens com maior MSF nas populações segregantes derivadas do dialelo. $\mathrm{O}$ aumento da MSF pode ser obtido com a maior concentração de genes dominantes, e o valor máximo esperado ( $\hat{\mathrm{Y}}_{\mathrm{D}}$ ) é de 14,30. Com exceção da Nativa, os demais progenitores encontram-se próximos a este valor, indicando que possuem elevada concentração de genes dominantes (Tabelas 4 e 5).
Na MSR o genitor com máxima homozigose dominante deverá apresentar $\hat{\mathrm{W}}_{\mathrm{r}}+\hat{\mathrm{V}}_{\mathrm{r}}$ de $-0,002053$, sendo Nativa o que mais se aproxima, apresentando $\hat{\mathrm{W}}_{\mathrm{r}}+\hat{\mathrm{V}}_{\mathrm{r}}$ de $-0,00012$. O valor máximo esperado $\left(\hat{\mathrm{Y}}_{\mathrm{D}}\right)$ de MSR é de 0,586 , e Nativa ultrapassou este valor $(0,646)$, indicando facilidade do melhoramento em obter aumento desse caráter.

A seleção de genótipos, nas gerações segregantes, que apresentem maior produção de matéria fresca da parte aérea pode ser conseguida sem dificuldades, já que o coeficiente de determinação genotípico é alto e predomina o efeito gênico aditivo. Já nos caracteres MSF e MSR, a predominância de efeitos gênicos de dominância sobre a variação genotípica indica que a seleção de genótipos com esses caracteres deva ser praticada em gerações com maior grau de endogamia.

Tabela 4. Estimativas das correlações entre os valores médios dos genitores $\left(\bar{Y}_{\mathrm{rr}}\right)$ e da soma da covariância, entre médias dos genitores e médias da r-ésima linha $\left(\hat{\mathrm{W}}_{\mathrm{r}}\right)$, e da variância entre médias da r-ésima linha $\left(\hat{\mathrm{V}}_{\mathrm{r}}\right)$, valores esperados das coordenadas $\hat{W}_{R}, \hat{V}_{R} e \hat{W}_{D}, \hat{V}_{D}$ e do valor predito para o genitor com máxima concentração de alelos dominantes $\left(\hat{\mathrm{Y}}_{\mathrm{D}}\right)$ e recessivos $\left(\hat{\mathrm{Y}}_{\mathrm{R}}\right)$, dos caracteres matéria fresca da parte aérea (MFPA), matéria seca das folhas (MSF) e matéria seca da raiz com transformação logarítmica (MSR), segundo o método de Hayman (1954a, 1954b). Viçosa, UFV, 1996.

\begin{tabular}{lcccccc}
\hline Caráter & \multicolumn{5}{c}{ Estimativas dos parâmetros } \\
\cline { 2 - 7 } & $\mathrm{r}\left(\overline{\mathrm{Y}}_{\mathrm{rr}}, \hat{\mathrm{W}}_{\mathrm{r}}+\hat{\mathrm{V}}_{\mathrm{r}}\right)$ & $\hat{\mathrm{W}}_{\mathrm{R}} ; \hat{\mathrm{V}}_{\mathrm{R}}$ & $\hat{\mathrm{W}}_{\mathrm{D}} ; \hat{\mathrm{V}}_{\mathrm{D}}$ & Equação de predição & Limite $\hat{\mathrm{Y}}_{\mathrm{R}}$ & Limite $\hat{\mathrm{Y}}_{\mathrm{D}}$ \\
\hline MFPA & $-0,4734$ & 1602,$0 ;$ & 107,$42 ;$ & $\hat{\mathrm{Y}}_{\mathrm{rr}}=313,9919-0,023166\left(\hat{\mathrm{W}}_{\mathrm{r}}+\hat{\mathrm{V}}_{\mathrm{r}}\right)$ & 237,6 & 311,3 \\
& & 1696,3 & 7,63 & & & \\
MSF & $-0,7518$ & 1,$815 ;$ & $-0,322 ;$ & $\hat{\mathrm{Y}}_{\mathrm{rr}}=14,18131-0,60966\left(\hat{\mathrm{W}}_{\mathrm{r}}+\hat{\mathrm{V}}_{\mathrm{r}}\right)$ & 10,708 & 14,303 \\
& & 3,881 & 0,122 & & & \\
Log (MSR) & $-0,8769$ & 0,$02293 ;$ & $-0,00252 ;$ & $\hat{\mathrm{Y}}_{\mathrm{rr}}=0,572251-6,518439\left(\hat{\mathrm{W}}_{\mathrm{r}}+\hat{\mathrm{V}}_{\mathrm{r}}\right)$ & 0,1694 & 0,5856 \\
& & 0,03887 & 0,00047 & &
\end{tabular}

Tabela 5. Valores da soma da covariância entre médias dos genitores e médias da r-ésima linha ( $\hat{\mathrm{W}}_{\mathrm{r}}$ ), e da variância entre médias da r-ésima linha $\left(\hat{\mathrm{V}}_{\mathrm{r}}\right)$; e médias dos caracteres matéria fresca da parte aérea (MFPA), matéria seca das folhas (MSF) e matéria seca da raiz com transformação logarítmica (MSR), segundo o método de Hayman (1954a, 1954b). Viçosa, UFV, 1996.

\begin{tabular}{|c|c|c|c|c|c|c|}
\hline \multirow[t]{2}{*}{ Cultivar } & \multicolumn{2}{|c|}{ MFPA } & \multicolumn{2}{|c|}{ MSF } & \multicolumn{2}{|c|}{$\log (\mathrm{MSR})$} \\
\hline & $\hat{\mathrm{W}}_{\mathrm{r}}+\hat{\mathrm{V}}_{\mathrm{r}}$ & $\begin{array}{c}\text { Média } \\
\text { (g/planta) }\end{array}$ & $\hat{\mathrm{W}}_{\mathrm{r}}+\hat{\mathrm{V}}_{\mathrm{r}}$ & $\begin{array}{c}\text { Média } \\
\text { (g/planta) }\end{array}$ & $\hat{\mathrm{W}}_{\mathrm{r}}+\hat{\mathrm{V}}_{\mathrm{r}}$ & Média $^{(1)}$ \\
\hline Grand Rapids & 2366,2 & 285 & 2,1260 & 13,54 & 0,02953 & 0,409 \\
\hline Maravilha de Verão & 1365,4 & 321 & 0,9163 & 13,47 & 0,04564 & 0,296 \\
\hline Mimosa & 1067,7 & 265 & 0,8572 & 13,12 & 0,01660 & 0,470 \\
\hline Nativa & 1808,0 & 219 & 3,7597 & 11,12 & $-0,00012$ & 0,646 \\
\hline Regina de Verão & 182,5 & 307 & 1,4880 & 13,37 & 0,01943 & 0,398 \\
\hline Vitória de Verão & 604,0 & 317 & 2,7741 & 13,20 & 0,01219 & 0,411 \\
\hline
\end{tabular}

${ }^{(1)}$ Médias obtidas a partir de dados da matéria seca da raiz (g/planta) com transformação logarítmica. 


\section{Conclusões}

1. No caráter matéria fresca da parte aérea, a variação de natureza aditiva contribui predominantemente para o seu controle gênico.

2. Na matéria seca de folhas e matéria seca da raiz os efeitos gênicos de dominância são mais importantes.

3 . Há evidência de epistasia nos caracteres matéria seca da parte aérea, número de folhas e comprimento do caule.

4. Há dominância parcial na matéria fresca da parte aérea, e sobredominância na matéria seca das folhas e da matéria seca da raiz.

5. Apresentam maior concentração de alelos favoráveis os genitores: a) matéria fresca da parte aérea: Regina de Verão e Vitória de Verão; b) matéria seca das folhas: Maravilha de Verão, Mimosa e Regina de Verão; c) matéria seca da raiz: Nativa.

\section{Referências}

AMARAL JÚNIOR,A. T. do; CASALI, V. W. D.; CRUZ, C. D.; FINGER, F. L. Inferências genéticas na produção e qualidade de tomateiro sob cruzamento dialélico. Pesquisa Agropecuária Brasileira, Brasília, v. 34, n. 8, p. 1407-1416, ago. 1999

COMISSÃO DE FERTILIDADE DO SOLO DO ESTADO DE MINAS GERAIS (Lavras, MG). Recomendação para uso de corretivos e fertilizantes em Minas Gerais: $4^{\text {a }}$. aproximação. Lavras, 1989. 176 p.

CRUZ, C. D. Programa Genes: aplicativo computacional em genética e estatística. Viçosa : Editora da UFV, 1997. 442 p

CRUZ, C. D.; REGAZZI,A. J. Modelos biométricos aplicados ao melhoramento genético. Viçosa : Imprensa Universitária, 1994. 378 p.

FERREIRA, P. E. On Jinks-Hayman's analysis of half diallels. Revista Brasileira de Genética, Ribeirão Preto, v. 8, n. 1 , p. $149-155,1985$

HAYMAN, B. I. The analysis of variance of diallel tables Biometrics, Washington, v. 10, p. 235-244, 1954a.

HAYMAN, B. I. The theory and analysis of diallel crosses Genetics, Bethesda, v. 39, n. 6, p. 789-809, 1954b.
JINKS, J. L.; HAYMAN, B. I. The analysis of diallel crosses. Maize Genetics Cooperation Newsletter, Columbia, v. 27, p. 48-54, 1953

MALUF, W. R.; MIRANDA, J. E. C. de; CAMPOS, J. P. de. Análise genética de um cruzamento dialélico de cultivares de tomate. I. Características referentes à produção de frutos. Pesquisa Agropecuária Brasileira, Brasília, v. 17 , n. 4, p. 633-641, abr. 1982

MATHER, K.; JINKS, J. L. Introdução à genética biométrica. Ribeirão Preto : Sociedade Brasileira de Genética, 1984. 242 p.

MIRANDA, J. E. C. de; MALUF, W. R.; CAMPOS, J. P. de. Análise genética de um cruzamento dialélico de cultivares de tomate. II. Características vegetativas. Pesquisa Agropecuária Brasileira, Brasília, v. 17, n. 5, p. 767-773, maio 1982

OLIVEIRA, V. R. Diversidade genética em pimentão (Capsicum annuum L.) e controle gênico da tolerância ao baixo teor de fósforo no solo. Viçosa : UFV, 1997. 108 p. Tese de Doutorado.

RAMALHO, M. A. P.; SANTOS, J. B. dos; ZIMERMANN, M. J. O. Genética quantitativa em plantas autógamas: aplicações ao melhoramento do feijoeiro. Goiânia : Editora da UFG, 1993. 271 p.

RYDER, E. J. Breeding vegetable crops. In: RYDER, E. J. (Ed.). Lettuce breeding. Westport : AVI, 1986. p. $433-474$

SINGH, R. K.; CHAUDHARY, B. D. Biometrical methods in quantitative genetic analysis. New Delhi : Kalyani, 1979. 304 p.

VECCHIA, P. T. D.; KIKUCHI, M. "Glória": nova cultivar de alface lisa resistente ao florescimento prematuro. Horticultura Brasileira, Brasília, v. 7, n. 2, p. 29, nov. 1989a.

VECCHIA, P. T. D.; KIKUCHI, M. "Verônica": nova cultivar de alface crespa resistente ao florescimento prematuro. Horticultura Brasileira, Brasília, v. 7, n. 2, p. 29-30, nov. 1989b.

VECCHIA, P. T. D.; KOCH, P. S.; KIKUCHI, M. "Vera": nova cultivar de alface crespa resistente ao florescimento prematuro. Horticultura Brasileira, Brasília, v. 17, n. 2 , p. 171, jul. 1999

VENCOVSKY, R.; BARRIGA, P. Genética biométrica no fitomelhoramento. Ribeirão Preto : Sociedade Brasileira de Genética, 1992. 486 p. 